\title{
Narrativas de la violencia de género en estudiantes de la Universidad Libre, Seccional Bogotá: conceptos, actitudes y prácticas sociales*
}

\author{
[Artículos]
}

\author{
Andrea Mazuera Ayala* \\ Paula Mazuera Ayala ${ }^{* * *}$ \\ Gloria Andrea Mahecha Sánchez ${ }^{* * * *}$
}

Recibido: 10 febrero de 2021

Aceptado: 6 de mayo de 2021

\begin{abstract}
* El presente manuscrito es producto del proyecto de investigación "Tendencias contemporáneas en la sistematización civilista. Segunda fase: las personas" del Grupo de Investigación de Derecho Privado y del Proceso, Gustavo Vanegas Torres, adscrito a la Universidad Libre, Bogotá, Colombia.

** Comunicadora Social, magíster en Administración del Desarrollo Humano y Organizacional y magíster en Lingüística. Docente y directora de Bienestar Institucional en la Universidad Libre, Colombia. Miembro del Grupo de Investigación en Reanimación, Urgencias y Simulación GIRUS, de la Universidad Tecnológica de Pereira, Colombia. Correo electrónico: andrea.mazuera@unilibre.edu.co; ORCID: https://orcid.org/0000-0002-5806-8206

${ }_{* * *}$ Abogada, especialista en Derecho Constitucional, especialista en Gerencia en Servicios de la Salud, magíster en Derecho y doctora en Derecho. Docente investigadora de la Universidad Libre, Colombia, categoría Junior Colciencias. Es integrante del grupo de investigación en Derecho Privado y del Proceso, Gustavo Vanegas Torres. Correo electrónico: paula.mazueraa@unilibre.edu.co; ORCID: https://orcid.org/0000-0003-0679-7149

${ }_{* * * *}$ Abogada, magíster en Derecho Administrativo y candidata a doctora en Derecho. Docente investigadora de la Universidad Libre, Colombia, categoría Junior Colciencias. Miembro del grupo de investigación en Derecho Privado y del Proceso, Gustavo Vanegas Torres. Correo electrónico: gloriaa.mahechas@unilibre.edu.co; ORCID: https://orcid.org/0000-0002-3588-6847
\end{abstract}


Citar como:

Mazuera Ayala, A., Mazuera Ayala, P. y Mahecha Sánchez, G. A. (2021). Narrativas de la violencia de género en estudiantes de la Universidad Libre, Seccional Bogotá: conceptos, actitudes y prácticas sociales. Revista IUSTA, (55).

https://doi.org/10.15332/25005286.6855

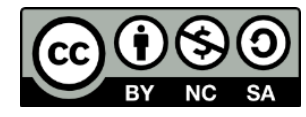

\section{Resumen}

El género representa actualmente un reto de inclusión educativa en el contexto universitario. El presente artículo busca caracterizar los conceptos, actitudes y prácticas sociales relacionados con la violencia de género de los estudiantes del programa de Derecho de la Universidad Libre, en el marco de la asignatura Lectura Crítica. Desde las categorías principales se identifican subcategorías que dan cuenta de conceptos que transitan entre el sentido común y lo normativo jurídico, actitudes que se apoyan en las experiencias propias, así como en la proyección en el otro. Por último, desde las prácticas sociales, se identifica una tendencia a actuar y tomar partido ante estas situaciones.

Palabras clave: estudiantes, narrativas, prácticas sociales, universidad, violencia de género.

\section{Narratives of gender violence in students of the Universidad Libre, Bogotá Campus: concepts, attitudes and social practices}

\section{Abstract}

Gender currently represents a challenge for educational inclusion. This study seeks to characterize the concepts, attitudes and social practices related to gender violence of Law students of the Universidad Libre, within the framework of the subject Critical Reading. From the main 
categories, subcategories are identified that account for concepts that move between common sense and legal regulations, attitudes that are based on their own experiences, as well as on the projection on the other, finally, from social practices, a tendency to act and take sides in these situations is identified.

Keywords: students, narratives, social practices, university, gender violence.

\section{Narrativas da violência de gênero em estudantes da Universidad Libre, sede Bogotá: conceitos, atitudes e práticas sociais}

\section{Resumo}

O gênero representa atualmente um desafio de inclusão educacional no contexto universitário. Neste artigo, pretende-se caracterizar os conceitos, as atitudes e as práticas sociais relacionados com a violência de gênero dos estudantes do curso de Direito da Universidad Libre, Colômbia, no âmbito da disciplina de leitura crítica. A partir das categorias principais, foram identificadas subcategorias que evidenciam conceitos que transitam entre o sentido comum e o normativo jurídico, atitudes que estão apoiadas nas experiências próprias bem como na projeção no outro; por último, a partir das práticas sociais, é identificada tendência em atuar e tomar partido ante essas situações.

Palavras-chave: estudantes, narrativas, práticas sociais, universidade, violência de gênero. 
Cuando un discurso es de tal modo

arrastrado por su propia fuerza en la deriva de lo inactual, deportado fuera de toda gregariedad, no le queda más que ser el lugar, por exiguo que sea, de una afirmación.

ROLAND BARTHES (1998, p. 11)

\section{Introducción}

Tradicionalmente, el derecho civil ha regulado aspectos personales y patrimoniales de las personas, sean estas naturales o jurídicas, para las primeras ha incluido el sistema civilista, el respeto y la protección de los derechos subjetivos de los que son titulares las personas, con el propósito de promover el desarrollo de los individuos en sociedad. Es innegable que la transformación social y la de las instituciones conlleva un mayor dinamismo en la regulación normativa necesaria para el respeto del individuo, la familia y la sociedad. Por ello, se evidencia la necesidad de optimizar sistemas jurídicos que respondan a las necesidades de las personas, entendidas como sujetos de derechos.

En este contexto, la comprensión de lo humano, así como de los conceptos de individuo y de género, adquiere relevancia al momento de optimizar los significados y la forma como el derecho responde a las realidades propias de las personas, en aras siempre del desarrollo humano en todas sus dimensiones. Se hace necesario visibilizar el alcance de expresiones relevantes para la comprensión de lo humano, de su dignidad y de la necesidad de no discriminación.

En este sentido, cobra relevancia el cuestionamiento que da lugar al presente artículo: ċlas narrativas de violencia y discriminación de los estudiantes de la Universidad Libre en la Seccional Bogotá evidencian la necesidad de revisar la noción de persona, propia de la sistematización 
civilista colombiana, y con esta de toda norma que ampare el reconocimiento de la dignidad humana y del derecho a no ser discriminado?

\section{Metodología}

Con el propósito de analizar el problema de investigación de manera deductiva, revisar la norma civilista y su contexto histórico y evolutivo, se emplearon estrategias de estudio focalizado que permitieron reconocer la capacidad del sistema normativo de la Universidad Libre, Seccional Bogotá, en términos de protección de la comunidad académica en torno al respeto y la no discriminación de sus estudiantes. Este proceso permitió identificar si en las narrativas de los estudiantes el concepto de persona y su protección permiten alcanzar el reconocimiento de la dignidad e individualidad que les son propios.

En este sentido, la investigación se enmarcó en el paradigma comprensivo cualitativo, que permite la descripción, interpretación y compresión de fenómenos sociales. El estudio se llevó a cabo en la Universidad Libre, Seccional Bogotá, durante un taller de reflexión sobre la violencia de género, con estudiantes de primero y segundo año de la Facultad de Derecho, en el cual se les invitó a contestar preguntas relacionadas con violencia de género dentro y fuera del contexto universitario. En dicho taller se obtuvieron narrativas escritas de cada uno de los 19 estudiantes participantes.

Las preguntas buscaban que el estudiante definiera la violencia de género, describiera los tipos que conoce, las bases jurídicas que la tipifican y la protección de la justicia a las personas que la padecen. Otro grupo de preguntas se enfocó en determinar las actitudes de los estudiantes, para comprender las narrativas desde el testimonio y el relato como elementos 
de la vivencia, como voces que surgen de las huellas culturales y sociales que pretenden revelar, y exteriorizar los aspectos injustos del contexto donde se inscribe y se identifica.

La definición de categorías se llevó a cabo comparando las narrativas recibidas en los diferentes grupos de preguntas realizadas e interrelacionadas a través de la definición de subcategorías, como interpretaciones abstractas construidas en conjuntos de palabras y afirmaciones utilizadas para explicar en sentido general las narrativas de los estudiantes. Estas no se asumieron como enunciados literales, sino como proposiciones o palabras que están entretejidas en las narraciones recibidas. En este sentido, se determinaron tres categorías que surgieron del propósito mismo de la investigación y que condensan el todo explicativo de relaciones.

Para analizar estas categorías se estableció una estrategia dividida en dos fases. En la primera, descriptiva-comprensiva, se caracterizaron los conceptos asociados a la temática propuesta, se definió como categoría central "Narrativas de la Violencia de Género" y se interrelacionó con las categorías principales: 1) "Conceptos", referido a los conceptos de los estudiantes, al conocimiento que tienen sobre el tema, en el sentido de que los conceptos del estudiante pertenecen al ámbito del saber conocer; 2) "Actitudes", aquello que el estudiante piensa y siente sobre la violencia de género - enmarcado en el ámbito del saber ser-; y 3) "Prácticas Sociales", definidas desde el actuar del estudiante frente a la violencia de género, enmarcadas en el ámbito del saber hacer.

Estas categorías principales se conectaron con subcategorías en un proceso descendente que se definió para cada una de las categorías principales; así, para la categoría conceptos, se construyeron las subcategorías: 1) "Tipos de Violencia”, referida a un saber inicial, es decir, a los conceptos básicos con 
los cuales se identifican diferentes formas de violencia; y 2) "Estados de Afectación”, desde la cual el estudiante relaciona los conceptos básicos mencionados con otros que permiten identificar una visión más holística desde su perspectiva.

Igualmente, se determinaron las subcategorías “Ámbito Normativo”, en relación con los conceptos jurídicos que el estudiante reconoce en la tipificación de la violencia de género; y "Garantía”, a través de la cual se relacionan los conceptos asociados a los derechos de las personas víctimas de violencia de género.

En cuanto a la segunda categoría, “Actitudes”, se definieron tres subcategorías: 1) "Mi Experiencia”, referente al sentir propio del estudiante, en el contexto de su narración, es decir, los términos en que el estudiante ha percibido y vivido la violencia de género y los sentimientos que esta le ha producido; 2) "Ejemplo", que consiste en el hecho narrado como un suceso que no es de la vivencia propia, pero que es un referente para la experiencia que, sin embargo, produce en el estudiante un deseo de cuestionarlo, de someterlo al escrutinio del propio sistema de referencia; y 3) "La Experiencia del Otro", que parte de reconocer que en la narrativa el estudiante no actúa como protagonista del acto de violencia de género, pero se siente afectado, es una experiencia que permea la propia vivencia. La tercera categoría "Prácticas Sociales" relaciona las subcategorías 1) "Intervención", referida en la narración a la forma en la que el estudiante actuaría si fuera testigo de un acto de violencia de género; 2) "Buscar Ayuda”, que se refiere a las instancias a las que el estudiante recurriría en busca de apoyo; y 3) "Denuncia", que remite a los mecanismos de acción que el estudiante tiene para contener la violencia de género.

En la segunda fase, comprensiva-interpretativa, se partió de las producciones textuales de los participantes para llevar a cabo una 
codificación abierta, en la cual se identificaron frases que describen las ideas y concepciones de los estudiantes acerca del tema propuesto; a cada frase se le asignaron códigos que surgieron de los datos obtenidos por los estudiantes y posteriormente estos datos se agruparon vinculando diferentes segmentos con conceptos, en función de alguna propiedad o elemento común. A los textos resultantes de las transcripciones se les realizó un análisis de contenido (Bardin, 1996) desde un proceso inductivo de identificación de palabras y frases con sentido, utilizando los parámetros y categorías de la fase descriptiva.

Las narrativas expresadas por los estudiantes a través de sus construcciones textuales permitieron ver las huellas del discurso en los conocimientos, actitudes y prácticas sociales, relacionadas en el segmento anterior. Esta construcción de sentido se realizó a través del análisis del uso de la primera persona en la narrativa del estudiante, así como del ejemplo como forma discursiva, a partir de los cuales las oraciones conectan los conceptos, actitudes y prácticas sociales con las cuales se interrelacionan las subcategorías.

Finalmente, a través de una construcción colectiva y colaborativa, se propuso un protocolo para abordar las diferentes violencias de género, que considere las necesidades de los miembros de la comunidad unilibrista, bajo una fundamentación jurídica que reconoce la perspectiva de género en el ordenamiento colombiano, los conceptos principales asociados al enfoque de género y diferencial que deben reconocerse en la Institución, los ámbitos de protección y las formas de denuncia, las diferentes formas de socialización de las violencias de género y los tipos de intervención. 


\section{Género y representación en contextos educativos}

Colombia ha contado históricamente con instituciones donde prima la imposición sin discusión y donde la revisión de sus propios sistemas normativos civilistas ha sido mínima (Rodríguez, 2014). De ahí que sea necesario, tomando como grupo focal a la comunidad estudiantil de la Universidad Libre, Seccional Bogotá, reconocer los conceptos vigentes desde lo humano, entendiendo su estructura, comprensión, formas, dignidad y no discriminación. De esta manera, a partir de la realidad que viven los estudiantes, es preciso identificar la necesidad o no de incorporar en normas institucionales, locales o nacionales, sistemas normativos y políticas institucionales que reflejen el respeto al ser humano y su no discriminación.

En este sentido, la experiencia de la violencia ejercida por la condición de género tiene múltiples matices, debido a la construcción subjetiva de las realidades de las personas, en la que influyen su condición histórica, el contexto desde el propio sistema de referencia, el tipo de violencia, la concepción de esta y las vivencias, que resultan ser el lienzo sobre el cual se plasman las narrativas.

Por consiguiente, es necesario entender la construcción del sujeto desde la propia condición de género, identificar cómo se nombra y cómo es nombrado a través del relato de la propia experiencia violenta. Es así como el texto (la narrativa) revela los rasgos de la emoción, la actitud y la expresión del cuerpo como síntomas que se manifiestan en la palabra.

De acuerdo con lo anterior, la Universidad Libre, Seccional Bogotá, ha venido trabajando en un protocolo de intervención frente a la violencia por la condición de género de los estudiantes, que pretende establecer acciones de prevención, detección y tratamiento de este tipo de violencia, lo que hace necesario entender las diferentes formas en las que los miembros de 
la comunidad universitaria comprenden este fenómeno, lo narran y lo subjetivan.

La condición de género de las personas representa actualmente para el contexto universitario un reto en cuanto a la educación inclusiva, puesto que implica la implementación y modificación de políticas institucionales que tengan en cuenta la diversidad, la cultura y las nuevas prácticas educativas desde la perspectiva diferencial de género. Así lo evidencia el documento Enfoque e identidades de género para los Lineamientos Política de Educación Superior Inclusiva, desarrollado por el Ministerio de Educación Nacional (MEN, 2018), en el cual se asigna especial importancia al género, especialmente mujeres y población LGBTI, por cuanto están más expuestas a la violencia, la discriminación y el abandono escolar. Igualmente, se pueden observar diferencias sustanciales entre las oportunidades de acceso a la educación, la permanencia en el sistema y las oportunidades laborales, entre hombres, mujeres o quienes tienen una identidad sexual en una categoría diferente (MEN, 2018).

En este sentido, se podría afirmar que la diferencia de género aún justifica un modelo de desigualdad en el que se legitima la superioridad tradicional de lo masculino sobre los sujetos femeninos o feminizados, considerados débiles, vulnerables o incapaces. "El sistema de asignación de una identidad de género diametralmente opuesto para cada sexo es dicotómico y jerarquizado, pero además, el lado masculino es el referente, el que domina, y define a su opuesto en la negación” (Facio y Fries, 2005, p. 279). Entonces, la condición de género, en función de lo masculino y lo femenino, se utiliza para asignar arquetipos ideológicos mediante discursos que perpetúan las diferencias. Estos se basan en la negación de la identidad, de la sensibilidad y de las capacidades -iguales en cuanto a la condición biológica - de las que todas las personas son portadoras, y 
diferentes en la concepción y ejecución de ellas - de acuerdo con la propia identidad y autonomía-.

\section{Narrar la violencia}

Asumir la narración como una práctica social en la cual el sujeto se representa a sí mismo en un contexto determinado implica comprender categorías de representación en las cuales los individuos ponen de manifiesto sus reflexiones, sus experiencias y sus interpretaciones. La palabra se manifiesta como un síntoma en el cual el sujeto se define a sí mismo como víctima o como no víctima, al mismo tiempo que evidencia unas marcas culturales de interacción con el contexto que aportan significados a la construcción de la propia identidad.

Entender las narrativas de la violencia es comprender también la gramática de los acontecimientos y el lugar que ocupa la persona en esta experiencia, porque "la experiencia no es ni lo que hacemos ni lo que nos hace, sino lo que nos deshace" (Mèlich, 2012, p. 67). En este sentido, la narrativa se transforma en un habitar en el acontecimiento, en la experiencia, en la capacidad de quien narra de identificarse, de aprender, de reflexionar y transformarse. Por lo tanto, requiere la comprensión de la palabra como:

Elección sujeta o no a un control consciente, se realiza de acuerdo con unos parámetros contextuales que incluyen la situación, los propósitos de quien la realiza y las características de los destinatarios, entre otros. Estos parámetros son de tipo cognitivo y sociocultural, son dinámicos y pueden estar sujetos a revisión, negociación y cambio. (Calsamiglia y Tuson, 2002, p. 15)

Aquí la experiencia es una interpretación de los acontecimientos que se realiza en la subjetividad del individuo, tanto como en la gramática 
colectiva: "Padecemos experiencias, aprendemos de las experiencias que nos suceden, pero podemos establecer relaciones con las experiencias que en cada momento de nuestras vidas nos hacen ser diferentes de quienes éramos antes" (Mèlich, 2012, p. 69).

La narración es característica de la experiencia y apela a la memoria, al testimonio y a la remembranza, lo que se constituye en propiedad del observador, quien, a través del ejercicio de la palabra, del lenguaje, observa sobre lo observado, con esto logra no solo constituirse a sí mismo sino también a los otros, a aquellos que escuchan. "Pero sobre todo, se enfrenta al narrar. El narrador toma lo que narra de la experiencia; la suya propia o la transmitida, la toma a su vez, en experiencias de aquellos que escuchan su historia” (Benjamin, 1998, p. 115).

Por tanto, narrar la violencia es transitar entre dos opuestos que se unen: por un lado, la violencia, como acto que se comente sobre una persona en cuanto persona, y por el otro, el lenguaje como expresión, como medio, como huella del acontecimiento y que se desdibuja en la dimensión temporal de lo narrable y lo narrado (Benjamin, 1998, p. 18).

En este sentido, a través del lenguaje se transmite o representa una realidad, porque la experiencia es comunicable y, por tanto, sujeta de representación lingüística, digna de ser analizada como medio de acción social, que permite desvelar los conceptos, actitudes y creencias respecto del fenómeno de la violencia de género:

La narración [...] es, de por sí, la forma similarmente artesanal de la comunicación, no se propone transmitir, como lo haría la información o el parte, el "puro" asunto en sí. Más bien lo sumerge en la vida del comunicante, para poder luego recuperarlo. (Benjamin, 1998, p. 119) 
La narración es un entramado de relaciones que en su contenido y estructura dejan ver la huella del narrador, de la interacción:

El hablante pone en juego su dominio de la lengua, para elegir, dentro de sus posibilidades, aquellos elementos que le son útiles para cada ocasión comunicativa [...] la elección que se lleva a cabo para adecuarse a la situación, y la elección que se lleva a cabo para lograr efectos singulares con una función estética, persuasiva o argumentativa. (Calsamiglia y Tuso, 2002, p. 325)

Como género fundamental, narrar implica deshacer, deshacerse y volver a ser, puesto que la narración "mantiene y transforma a personas y relaciones" (Van Dijk, 2008, p. 272), se da en un contexto que es validado por el narrador desde su propia experiencia narrable, esto es, cuando quien vive la experiencia o la percibe a través de sus propios sentidos dibuja un contexto y le da sentido a su propia experiencia. Narrar es entonces la construcción propia de una experiencia. Por tanto, la narración puede "involucrar, hablar de representaciones visuales, observarlas y señalarlas" (Van Dijk, 2008, p. 272), de una manera más amplia:

Era mi primer año de Derecho en la Libre, conocí a un muchacho y después fuimos novios, pero con el paso del tiempo hubo varios problemas entre los cuales menciono: infidelidad, malas palabras y hasta golpes por parte de él hacia mí, al principio yo lo justificaba todo, porque estaba enamorada, pero al final todo acabó en una denuncia, mas, sin embargo, le tengo que ver todos los días la cara en la Universidad, a pesar de mi medida de protección. (E17, comunicación personal, 3 de marzo de 2020)

En esta narración se encuentra un acto personal, en el que el narrador se ubica en un tiempo pasado (primer año) y un espacio (la Universidad Libre) que lo conducen por la remembranza, en este caso como 
protagonista de una experiencia; el sujeto se pasea por un discurso continuum que nace, se desarrolla y no muere, en este aún persiste la necesidad, porque al hecho narrado no se le ha dado un cierre ("le tengo que ver todos los días la cara en la Universidad a pesar de mi medida de protección”). La necesidad está tácita en la narración, y se presenta como un síntoma que se manifiesta en el sentimiento de una desprotección igualmente tácita. Quizás se trate de un reclamo, un otro que debe hacer por mí lo que yo no puedo hacer, y como ese otro no lo hace, yo lo responsabilizo de mi sufrimiento.

El sentimiento también se justifica en la palabra, como una figura que permanece - "yo lo justificaba todo, porque estaba enamorada” (E17, comunicación personal, 3 de marzo de 2020)-, una especie de totalidad en la que el sujeto lo designa todo en una especie de añoranza, pero también de sufrimiento, el otro está presente en su discurso, un otro ideal, "la propiedad del deseo no puede producir sino una impropiedad del enunciado" (Barthes, 1998, p. 28). Por tanto, "estaba enamorada" construye un rastro, es una suerte de pasado y presente para el sujeto que se dibuja en el síntoma, como expresión subjetiva del inconsciente. Enamorada es el todo. "Cada palabra se convierte en estímulo motriz o cinestésico para evocar la constelación lingüística que lo acompaña” (Maceiras, 2002, p. 127), estar enamorado adquiere también un significado en la cultura, es decir, en la gramática de los acontecimientos, historizados en un discurso aprendido y concretado a través de la experiencia:

Cuando pequeña fui agredida sexualmente por un familiar, esto causó demasiados miedos e inseguridades, recuerdo que cuando hablé y conté la situación me respondieron que la culpa era mía porque algo debe hacer la mujer para provocar al hombre, por muchos años me sentí culpable. (E19, comunicación personal, 3 de marzo de 2020) 
La cultura imperante en esta sociedad patriarcal también conlleva, a su vez, una gramática de la diferencia, del estereotipo que se materializa en la palabra - "algo debe hacer la mujer para provocar al hombre" (E19, comunicación personal, 3 de marzo de 2020)-:

[...] por lo tanto, el concepto de feminidad en el cual se ve obligada a vivir la mujer, es una concepción de vasallaje propicio para la perpetuación de los intereses masculinos, y que hace a la mujer una habitante extraña y sumisa de una condición vital que no ha sido elegida [...]. (Mazuera, 2019, p. 67)

El sistema de roles binarios perpetúa la culpa basada en la condición de género, establecida por la superioridad masculina, que implica que el hombre puede poseer un cuerpo femenino, aun cuando esto implique pasar por encima del otro. La violencia ejercida sobre la otra "alberga dentro de sí un elemento adicional de arbitrariedad" (Arendt, 2006, p. 11), que también se da en el binario genérico, donde la culpa es una especie de castigo moral por la supuesta provocación y a su vez un autocastigo que se perpetúa en el tiempo, en la psiquis del sujeto. "Desde la infancia se condicionan los comportamientos que pueden ser exhibidos en presencia de otros, reforzándolos de manera positiva, y se castigan o se ignoran los que no son permitidos socialmente" (Juárez, 2020).

Sentirse culpable - "por muchos años me sentí culpable" (E19, comunicación personal, 3 de marzo de 2020) - se presenta como una resistencia del sujeto a reconocer en el otro su responsabilidad, a percatarse de la agresión sobre su cuerpo y a desear el castigo. Esa concepción de la culpa como castigo impuesto y autoimpuesto se legitima en la idea de la familia como base infranqueable de la sociedad; una familia que hay que proteger, ergo la puesta en conocimiento de un acto inmoral por cualquiera de sus miembros rompería su santidad. En la 
concepción tradicional de la familia es mejor dejar el castigo para la niña, sus miedos e inseguridades, por tanto, le pertenecen solo a ella. En este caso, la violencia a la que es sometida la otrora niña es profundamente transformadora, pues dicha experiencia la sitúa en el lugar de los acontecimientos no como víctima sino como actor de responsabilidad, su experiencia está mediada por la interacción social, justificada en normas y valores culturales.

La narración del hecho violento es una muestra del sentir, del pensar y el actuar de una voz que quiere ser escuchada, catarsis obligada que busca exorcizar una afección y seguir adelante-"por muchos años me sentí culpable" (E19, comunicación personal, 3 de marzo de 2020)-. Esto conlleva el deseo imperante de superarlo, aunque no se haya hecho, un recuerdo que implica la añoranza de dejarlo atrás. "Toda palabra libera la plenitud de su significado solo cuando se entrelaza en frases o relatos" (Maceiras, 2002, p. 290) para convertirse en algo que en su expresión es susceptible de superarse.

\section{Las personas}

La persona, en términos formales, es aquella que está considerada como un sujeto dotado de derechos y obligaciones, también de personalidad jurídica, que le permite desarrollarse en el mundo del derecho, con capacidades excepcionales que le diferencian de los demás seres vivos. En cuanto conciencia y representación, la persona es un agente que es capaz de responder, está dotado de emociones y sentimientos que lo ponen en condición de establecer esferas de sentido, hacer elecciones y vivir de acuerdo con estas.

La concepción jurídica de la categoría persona está presente en el Artículo 74 del Código Civil colombiano, que determina que "son personas todos 
los individuos de la especie humana, cualquiera que sea su edad, sexo, estirpe o condición" (Código Civil, 2018, p. 22).

Por lo tanto, el concepto "persona" podría abordarse desde dos puntos de vista. Por un lado, se puede considerar un sujeto susceptible de ser respondiente, de comprender y establecer relaciones, que pertenece a un entorno cultural particular (mediado por expresiones normativas de carácter social obligatorio que determinan el actuar y las relaciones con los demás); es un ser que está ubicado en el escenario de un espacio y un tiempo determinados, mediado por una historia, por un tiempo narrado y, por tanto, por un conjunto de relaciones que construyen su identidad. La persona también es un ser dotado de sufrimiento, que interpreta el mundo y lo sufre, pues vive en permanente tensión entre la carencia y la posibilidad.

Por otro lado, la persona es un ser biológico que, desde el punto de vista del derecho, surge a partir del nacimiento, esto es, al momento en el que ha sido expulsado del vientre materno y ha sobrevivido un instante siquiera, pues, quien muere en el claustro de la madre o no respira una vez afuera no se considera persona - a pesar de que existen normas que protegen al que está por nacer bajo la expectativa siempre de que nazca (C.C., art. 90 y 91, Colom.) -; la persona cuenta con una naturaleza provista de un cuerpo que se desarrolla y madura con el tiempo, y que además es finito, fenece, porque todo él está sometido a lo físico. Desde esta perspectiva biológica, las personas nacen con un sexo determinado, desde la comprensión binaria, como fenómeno biológico que es comprendido y compartido por una sociedad.

Desde el ámbito social, la persona es producto de la compresión colectiva y de la cultura, de acuerdo con esta se nombra y se identifica. La persona historizada por naturaleza, gramaticalmente definida, está en tensión 
permanente entre lo que puede, debe y quiere ser, un ser en falta que se interpreta y reinterpreta permanentemente. Clasificar a una persona como hombre o como mujer es una decisión social, a la cual por imperativo moral se ven sujetas las personas. Dicha perspectiva binaria "es lo suficientemente fuerte como para disciplinar los cuerpos cuando no se adaptan cómodamente a la lectura que se espera de ellos” (CIDH, 2015). Ahora bien, la persona también se constituye desde las emociones, de manera que quienes enfrentan una construcción de género que rompe el esquema binario, experimentan una tensión permanente entre lo que se es por imposición y lo que se quiere ser; porque esta acción implica dejar de ser lo que hasta el momento se ha determinado como el deber ser, el imperativo moral que obliga una práctica reflexiva de la realidad desde donde se sitúa no en ese deber ser, sino en la vulnerabilidad de sí mismo, en la posibilidad de encontrar su propia felicidad, realización e identidad.

Desde esta perspectiva, el género como categoría que le pertenece a las personas es, por tanto, lo que parece diferenciar la identidad masculina de la femenina, por ello no es lo mismo género y sexo, pues el género es entendido como una creación cultural y social de la que surgen características que establecen el comportamiento, las actitudes y los convencionalismos sociales; el sexo, por su parte, se considera una realidad biológica, por ello la compresión de lo que significa lo masculino o lo femenino, así como el ser hombre o ser mujer ha cambiado con el tiempo, la cultura y la sociedad.

La condición de género es concebida más allá de las características biológicas de los seres humanos, porque se trata de un constructo cultural visto desde el binarismo hombre/mujer, que refiere a roles y atributos que tradicionalmente la sociedad les ha asignado a estos. Por ejemplo, al sujeto femenino o feminizado se le adscribe el arquetipo de vulnerabilidad, 
reproducción, minoría, etc., mientras que al masculino se le otorgan arquetipos patriarcales como la producción, la fortaleza o la inteligencia. En un sentido más amplio, el género:

[...] tiene su base material en un fenómeno natural, de nacimiento que es el sexo, cuya desaparición no depende de la desaparición de las diferencias sexuales [...], pero sí depende de la conducta, los deseos, los imaginarios de las personas en el contexto social e individual sin referencia a la base biológica. (Facio y Fries, 2005, p. 268)

En este sentido, el concepto de género, más allá de referirse exclusivamente al binarismo hombre/mujer, implica otras miradas que se combinan y se integran con identidades no normativas, y que, por tanto, están en la base del estigma. De manera que si no se cumple con el mandato patriarcal, entonces, no se reconocen y respetan las diferencias y se perpetúa la acción violenta: "En ese sentido, la sexualidad puede ser entendida como un sistema de opresión que se articula con el género, pero tiene su propia lógica al establecer jerarquías entre la sexualidad normativa y las prácticas que se apartan de ella, estigmatizando a quienes las encarnan” (MEN, 2018, p. 32).

En el segundo punto de vista, la persona es un sujeto poseedor de derechos y deberes que solo a ella se le asignan, no hay entidad diferente a la de ser persona a la que se le pueda asignar deberes y derechos, puesto que estos se desarrollan en la conciencia moral, en la capacidad racional para responder.

La condición genérica de las personas es tenida en cuenta en las normas, Plata (2007) advierte que el derecho como organización jurídica se crea para la convivencia y coexistencia pacífica de los coasociados, es así que en las representaciones sociales de lo jurídico el Estado soporta su función teleológica de lograr el bien común para sus miembros, 
explicando la necesidad de una adecuación lingüística del derecho en el contexto social, pues a partir de las fórmulas jurídicas, los asociados ajustan sus comportamientos al orden establecido. (Mazuera, 2019, p. 19)

En este sentido, con la expedición de la Constitución Política de 1991, en Colombia se ha llevado a cabo un proceso de visibilización de la perspectiva de género y la protección en igualdad de los derechos de las personas. El Artículo 13 de dicha Carta contempla que:

Todas las personas nacen libres e iguales ante la ley, recibirán la misma protección y trato de las autoridades y gozarán de los mismos derechos, libertades y oportunidades sin ninguna discriminación por razones de sexo, raza, origen nacional o familiar, lengua, religión, opinión política o filosófica. El Estado promoverá las condiciones para que la igualdad sea real y efectiva y adoptará medidas en favor de grupos discriminados o marginados. El Estado protegerá especialmente a aquellas personas que, por su condición económica, física o mental, se encuentren en circunstancia de debilidad manifiesta y sancionará los abusos o maltratos que contra ellas se cometan. (C.P., 1991, art. 13, Colom.)

Asimismo, el Artículo 43 expresa: "La mujer y el hombre tienen iguales derechos y oportunidades, la mujer no podrá ser sometida a ninguna clase de discriminación [...]” (C.P., 1991, art. 43, Colom.). Dichos artículos se constituyen en una obligación para el Estado, que debe:

[...] promover políticas de prevención y cumplimiento efectivo que acometan no solo contra las violaciones a los derechos a la igualdad de género, sino también al tratamiento efectivo de sus causas, que propendan por hacer de la Constitución un texto de dinámica social en el cual las relaciones tiendan a la realidad real en condiciones de igualdad. (Mazuera, 2019, p. 50) 
Este principio fundamental de la dignidad humana se ve respaldado por una serie de normas nacionales e internacionales que buscan su aplicación efectiva, entre las cuales se encuentran: la Declaración Universal de Derechos Humanos, que en 1948 en su preámbulo y en los artículos 2, 6 y 7 específicamente señalan la igualdad de las personas como sujetos de derechos inalienables; el Pacto Internacional de Derechos Económicos, Sociales y Culturales (1966), que ratifica en el Artículo 2 el derecho que tienen las personas al respeto de su dignidad, sin distingo de raza, sexo, color, idioma, etc.; y el Pacto de Derechos Civiles y Políticos, que en el Artículo 3 busca garantizar a hombres y mujeres la igualdad y el goce de sus derechos.

Por su parte, la Convención Americana sobre Derechos Humanos "Pacto de San José de Costa Rica”, en el Artículo 5 señala que “Toda persona tiene derecho a que se respete su integridad física, psíquica y moral" y en el 24: "Todas las personas son iguales ante la Ley. En consecuencia, tienen derecho, sin discriminación a igual protección de la ley" (Convención Americana sobre Derechos Humanos, 1969).

La Convención sobre la eliminación de todas las Formas de Discriminación contra la Mujer (1979) ratificó que toda discriminación contra la mujer es una violación a los principios de igualdad de derechos y al respeto por la dignidad humana. Sobre todo, puso de manifiesto que con dichas violaciones se desconocen y minan las posibilidades que tienen las mujeres para desarrollar una vida digna en igualdad de condiciones, y limitan el acceso a espacios de participación y otros escenarios de la vida humana. La Convención Interamericana para Prevenir, Sancionar y Erradicar la Violencia Contra la Mujer (1994) visibilizó la necesidad de ofrecer protección especial a las mujeres, así como a la garantía de sus derechos. La Declaración de Beijing (1995) abordó "los objetivos de igualdad, 
desarrollo y paz para todas las mujeres del mundo, en interés de toda la humanidad" y ratificó el acuerdo de "defender los derechos y la dignidad humana intrínseca de las mujeres y los hombres” (OEA, 1995, p. 1). A partir del Protocolo Facultativo de la Convención sobre la Eliminación de todas las Formas de Discriminación contra la Mujer (1999), el Estado colombiano se comprometió a respetar los tratados internacionales que en materia de protección de la mujer frente a acciones violatorias por parte del Estado se llegaran a presentar. También cabe mencionar la Resolución 1335 de 2000, aprobada por el Consejo de Seguridad de la ONU, por medio de la cual se da tratamiento a la perspectiva de género en el conflicto armado y los procesos de paz.

Los Objetivos de Desarrollo del Milenio, fijados en el año 2000 por la Organización de Naciones Unidas y sus 189 países miembros, contemplan la perspectiva de género incluida en su objetivo $n .^{\circ} 3$, que aborda la igualdad entre los géneros y la autonomía de la mujer.

A nivel nacional, se suman una serie de normas y leyes que buscan la protección efectiva de las personas por su condición de género, pues es justo en esta que se construyen las relaciones sociales y donde se evidencian con mayor fuerza las desigualdades. Este es el caso de la Ley 82 de 1993, por medio de la cual se apoya a las mujeres cabeza de familia, y se reconoce su necesidad de protección especial y las de sus dependientes, en cuanto a salud, educación, programas de capacitación, desarrollo empresarial, cultural, entre otras políticas públicas que propendan por el acceso en igualdad de condiciones.

Asimismo, las leyes 294 de 1996 y 599 de 2000 abordan inicialmente la violencia intrafamiliar como un asunto de carácter público y ponen en evidencia una realidad que afecta no solo a las personas en el seno 
familiar, sino también en otros espacios, principalmente a las mujeres como fuerza reproductiva de la sociedad.

Las leyes mencionadas, actualizadas y complementadas, contemplan en su articulado medidas de protección específicas para los miembros de la familia cuando son víctimas de violencia, tales como el desalojo de la vivienda por parte del agresor en caso de que uno de los miembros corra peligro inminente, distanciamiento del victimario, protección especial a menores e incluso procesos de educación y reeducación para la prevención de la violencia intrafamiliar, así como sanciones económicas en cuanto al incumplimiento de dichas medidas de protección.

La Ley 731 de 2002 busca fortalecer a las mujeres rurales y brindarles acceso a recursos y oportunidades para cerrar la brecha ente el hombre y la mujer rural, eliminar los obstáculos, crear planes y programas que favorezcan su desarrollo productivo y los canales de comunicación adecuados para acceder a dichos programas, financiar actividades propias de lo rural, mejorar el acceso a créditos, financiación y prácticas empresariales que fortalezcan sus actividades económicas, así como garantizar la igualdad en el acceso a los servicios de salud, educación y espacios de participación en los cuales las mujeres tradicionalmente se vieron limitadas.

La Ley 823 de 2003, por medio de la cual se dictan normas sobre igualdad de oportunidades para las mujeres, por primera vez incluye, en el capítulo II, artículo 4, la obligación del Estado de incluir una perspectiva de género que favorezca la igualdad entre hombres y mujeres, evidenciada a través de los numerales 1 al 4 del mencionado artículo:

1. Adoptar criterios de género en las políticas, decisiones y acciones en todos los organismos públicos nacional y descentralizados. 
2. Adoptar las medidas administrativas para que las instituciones responsables cuenten con instrumentos adecuados para su ejecución.

3. Promover la adopción de indicadores de género en la producción de estadísticas de los organismos e instituciones públicas y privadas.

4. Divulgar los principios constitucionales, leyes e instrumentos internacionales suscritos por Colombia que consagren la igualdad real y efectiva de derechos y oportunidades de todas las personas, y en especial los relacionados con los derechos de las mujeres y las niñas. (Ley 823 de 2003, art. 4, Colom.)

En este sentido, la Ley 823 contempla una perspectiva diferencial de género que incluye dentro de los planes y proyectos del Estado políticas para la igualdad de las mujeres en las esferas pública y privada; así como para promover el acceso a estas diferentes instancias, sin discriminación y con respeto de su condición de género.

Otros avances en la perspectiva de género se dieron con la entrada en vigencia de la Ley 1009 de 2006, por medio de la cual se creó el Observatorio de Asuntos Género, a través de la Consejería Presidencial para la Equidad de la Mujer. Esta entidad busca, además de apoyar las políticas públicas relacionadas con la equidad de género, contar con información veraz sobre la situación de las mujeres en el país en escenarios como el conflicto armado, la participación política, la familia y los contextos rurales y urbanos.

La Ley 1257 de 2008, que tiene por objetivo la sensibilización y sanción de actos de discriminación y violencia contra las mujeres, pretende fortalecer espacios de comunicación y visibilización de la violencia por razones de género, tales como daño físico, psicológico, sexual y patrimonial. También 
propende por establecer medidas efectivas en materia de salud, educación, familia y trabajo, para garantizar condiciones equitativas para la mujer.

También cabe mencionar el Decreto 164 de 2010, que busca la integración intersectorial para la erradicación de la violencia contra las mujeres; la Ley 1468 de 2011, que modifica el Código Sustantivo del Trabajo en sus artículos 236, 239, 57 y 58 en relación con el descanso remunerado después del parto; la Ley 1542 de 2012, que modifica el artículo 74 del Código de Procedimiento Penal, frente a actos de violencia contra la mujer y los delitos de violencia intrafamiliar e inasistencia alimentaria, elevándolos más allá de querellables y desistibles; la Ley 1639 de 2013, por medio de la cual se toman medidas de protección frente a los delitos con ácidos; y el Decreto 1930 de 2013, que adopta la Política Nacional de Equidad de Género.

Otras regulaciones importantes en relación con la violencia de género son la Ley 1719 de 2014, que adopta medidas para garantizar el acceso a la justicia de las víctimas de violencia sexual, en especial la violencia sexual con ocasión del conflicto armado, y la Ley 1761 de 2015, "Rosa Elvira Cely", en la cual se tipifica el feminicidio como un delito autónomo, para garantizar la investigación y sanción de las violencias contra las mujeres por motivos de género y discriminación. Esta Ley también busca prevenir y erradicar dichas violencias y adoptar estrategias de sensibilización de la sociedad colombiana, con el propósito de garantizar el acceso de las mujeres a una vida libre de violencias que favorezca su desarrollo integral y su bienestar, de acuerdo con los principios de igualdad y no discriminación.

Igualmente, el Ministerio de Educación Nacional (MEN), dentro de los lineamientos de la Política de Educación Inclusiva, enmarca el concepto de bienestar en un enfoque de derechos que tiene como núcleo el respeto y 
fomento de la diversidad e interculturalidad con equidad, calidad y participación en los sistemas educativos. Asimismo, el Plan Decenal de Educación 2016-2026 tiene como desafío estratégico construir una sociedad en paz sobre una base de equidad, inclusión, respeto a la ética y equidad de género, promoviendo el acceso la educación y la permanencia estudiantil con enfoque diferencial y de calidad (MEN, 2017, p. 54).

\section{Conceptos asociados a la violencia de género}

\section{El género desde lo femenino}

La condición de género en razón al sujeto femenino implica grandes desigualdades respecto al masculino, tradicionalmente, a las mujeres se les asigna desde la infancia categorías como: lo bello y dulce, la reproducción y el recato, el cuidado de los otros y la abnegación, la virginidad y la sumisión, entre otros, todos ellos legitimados por una visión patriarcal imperante en la sociedad. Estos roles instaurados en el ámbito privado se podrían relacionar con los roles públicos en los que las mujeres se desenvuelven, donde se les sigue exigiendo ser personas recatadas. Aquellas mujeres que incursionan en profesiones asignadas tradicionalmente a los hombres son vistas con cierta desconfianza o tienen incluso salarios inferiores a los de sus pares masculinos.

En la educación, por ejemplo, aunque en el último decenio la proporción de mujeres que acceden a la educación superior, respecto de los hombres, es mayor en un $5.8 \%$ aproximadamente, los programas en los que se forman están asociados a lo "femenino". Por otra parte, las mujeres acceden en menor proporción a la educación posgradual, los cargos a los que aspiran son de menor categoría y las remuneraciones son significativamente menores a las de los varones que ocupan los mismos puestos: 
Un análisis desagregado de la matrícula por Núcleo Básico del Conocimiento (NBC) nos permite identificar mejor las características de esta segregación horizontal por sexo en la educación superior colombiana. Según los datos publicados por el [Sistema Nacional de Información de la Educación Superior] SNIES para el primer semestre de 2016, se puede apreciar la segregación de las mujeres en aquellas carreras que tradicionalmente se conocen como "femeninas", que están asociadas por lo general a una labor de cuidado y que no son altamente valoradas por la sociedad ni en lo simbólico ni en lo material, a pesar de su importancia para el bienestar social. En este grupo se encuentran formaciones como nutrición y dietética, terapias, enfermería, bacteriología, instrumentación quirúrgica, sociología, trabajo social y afines, psicología, bibliotecología y otros de ciencias sociales y humanas, odontología, salud pública, con más del 70 \% de participación femenina en la matrícula. (MEN, 2018, p. 24)

Las desigualdades de género no solo se perciben en la educación, la vida política es un desafío para las mujeres, pues su participación activa como candidatas y aspirantes a cargos de elección popular ha estado mediada por la tutela masculina y ha enfrentado tantas dificultades que el Estado ha determinado acciones afirmativas para su cumplimiento. Sin embargo, estas medidas no han sido suficientes para que las mujeres ocupen dichos cargos, en 2018, de los 108 senadores de la República, 25 eran mujeres, y de los 171 representantes a la cámara, solo 31 eran de género femenino, lo que indica que el $21.7 \%$ de los 258 congresistas eran mujeres. Además, la presencia femenina no solo es inferior en la cifra de participación, a esto se suma que muchas de las mujeres en dichas corporaciones se apropian del estereotipo patriarcal para encajar y obtener reconocimiento y aval, y otras tantas son objeto de burlas o se ven disminuidas en sus capacidades, de manera que dicha participación, que ha crecido tímidamente en los últimos años, también necesita ser pensada desde otros aspectos. 
En Colombia se expidió la Ley 581 de 2000 o llamada Ley de Cuotas, como cumplimiento a los artículos 13, 40 y 43 de la Constitución Política, con el propósito de otorgar a las mujeres la adecuada y efectiva participación en todos los niveles y ramas del poder público. Actualmente, se exige extender sus alcances, garantizar su cumplimiento y utilizarla como herramienta para generar un debate aún ausente sobre la participación de la mujer de manera más amplia y real.

Por otra parte, la mujer aún enfrenta grandes desafíos respecto a su seguridad, su individualidad y su condición femenina en el ámbito privado. Según un informe presentado por la revista Semana, entre 2018 y febrero de 2019 se cometieron 1080 asesinatos de mujeres, 2000 casos de abuso sexual denunciados, 500 casos de violencia intrafamiliar y 122000 casos de violencia específica contra la mujer (Semana, 6 de marzo de 2019).

Asimismo, las mujeres se enfrentan a conflictos simbólicos en la sociedad, pues una mujer que no encaja en el estereotipo requerido por la sociedad y los medios de comunicación, es vulnerada permanentemente en su identidad. Por ejemplo, en el contexto universitario se han observado situaciones asociadas al bullying o acoso y a la discriminación por razones económicas, sociales, culturales e identitarias, que han llegado incluso a generar problemas de acoso basados en la identidad de género entre los estudiantes y entre estos y sus docentes, lo que conlleva en muchos casos la deserción escolar. 


\section{Igualdad/equidad ${ }^{1}$}

La igualdad está definida como un principio constitucional que le asiste a todas las personas, es un marco normativo en el que se fundamenta la idea de un Estado en el que conviven personas capaces de ser y de hacer del mundo un espacio de igualdad de condiciones y de acceso a la vida en sociedad. Sin embargo, este concepto se ve permeado por variables como la libertad y el acceso a las diferentes dimensiones de la vida humana -biológica, social, cultural, psicológica, cognitiva, axiológica y existencial-, que deben ser garantizadas en el reconocimiento de la persona, de su identidad, de sus necesidades y de sus expectativas:

En el marco de una educación inclusiva, la igualdad de oportunidades se comprende fundamentalmente como la igualdad de acceso al sistema educativo, en todos los niveles de formación y sin segregación por áreas del conocimiento o disciplinas; supone garantizar las condiciones para la permanencia, y la superación de barreras que excluyen y discriminan [...] [a la población por su condición de género]. (MEN, 2018, p. 34)

La equidad tiene que ver con el reconocimiento de la diferencia como parte estructural de la sociedad, está representada en el mayor acceso a los servicios del Estado con capacidad incluyente.

\section{Diversidad sexual}

La diversidad sexual o diversidad sexo-genérica es entendida como:

[...] las posibilidades que tienen las personas de asumir, expresar y vivir su sexualidad, así como de asumir expresiones, preferencias u orientaciones e identidades sexuales. Parte del reconocimiento de que todos los cuerpos, todas las sensaciones y todos los deseos tienen derecho

\footnotetext{
${ }^{1}$ Los conceptos asociados a la violencia de género son tomados del documento del MEN (2018).
} 
a existir y manifestarse, sin más límites que el respeto a los derechos de las otras personas. (Conapred, 2016, p. 18)

Las personas con identidades sexuales no normativas frecuentemente se enfrentan a problemas de discriminación, y aunque en Colombia ya se ha comenzado a hablar sobre el tema, aún se observa prevención al respecto. En el sistema educativo universitario, específicamente, las cifras de personas con identidades sexuales diversas han aumentado, como muestra un estudio realizado en 2017 con población LGBTI en Bogotá, que identificó que de las 1139 personas encuestadas, 42 \% cuentan con estudios superiores (MEN, 2018, p. 28). Sin embargo, dicha población se ve enfrentada a diferentes formas de discriminación por razones de género, en este contexto, las personas transgénero son la población más vulnerable, lo que trae como consecuencia que prefieran vivir en un constante ocultamiento debido al temor de ser rechazadas.

En el Programa de Permanencia y Graduación con Calidad de la Universidad Libre se ha observado que la población con sexualidades no normativas enfrenta grandes temores respecto de las relaciones interpersonales entre sus compañeros y con sus docentes, pues a lo largo de su vida muchos de ellos han sido víctimas de conductas agresivas, violencia y matoneo, especialmente en los lugares en que recibieron su educación básica y en sus hogares. Este es un factor de alta importancia para la Institución, en cuanto que la población con sexualidades no normativas presenta alto riesgo de deserción, de manera que es preciso el establecimiento de políticas protectoras, así como la generación de un diálogo institucional permanente que construya redes de conversaciones e interacciones para la inclusión por razones asociadas al género.

La homofobia, la lesbofobia, la bifobia y la transfobia han permeado las estructuras de las instituciones educativas de muchas maneras y se han 
valido de prácticas como la presión por parte de directivas escolares para lograr traslados de docentes y estudiantes por discriminación en razón a su orientación sexual o identidad de género, o por el desarrollo de trabajos, por parte de docentes, tendientes al reconocimiento de los derechos de personas LGBTI. (Esguerra, 2011, p. 29)

\section{Enfoque diferencial}

Además de la violencia ejercida por la condición de género, las mujeres, lesbianas, gais, bisexuales, transexuales, intersexuales, queer, pansexuales, entre otros, se enfrentan a otros tipos de violencias relacionadas con el cuerpo, la religión, la raza, la cultura, la economía, etc., que los convierten en personas aún más susceptibles de ser víctimas. Por ejemplo, una persona gai afrodescendiente, una mujer pobre o una discapacitada tienen un riesgo mayor de ser víctimas de acoso y acciones violentas, dado que las ideologías acerca de las diferentes condiciones de las personas sumadas a la condición de género resultan intolerables para quienes se asumen física, mental y socialmente como "normales".

Asimismo, la discriminación por condiciones específicas como la raza, la economía, la cultura, entre otras, relacionadas con la condición de género, son permeadas por el binarismo de género (hombre/mujer), el heterosexismo y el cissexismo (forma de opresión por género). Por su parte, la discriminación y la violencia ocasionadas por la bifobia, la homofobia, la intersexfobia, la lesbofobia, la transfobia, la misógina, entre otras, responden a las expectativas sociales establecidas por la heteronormatividad y la cisnormatividad.

El enfoque diferencial se debe abordar como estrategia de reconocimiento para los grupos diversos de la sociedad, que son sujetos de especial protección debido a los riesgos a los que se enfrentan, de manera que se hace necesario "diseñar y ejecutar acciones para la transformación de las 
relaciones que reproducen las desigualdades entre individuos y grupos sociales" (Parada y Uribe, 2017, p. 2). En este sentido, el enfoque diferencial se concibe como el reconocimiento de los sujetos dentro de un contexto determinado, que a su vez propicia estilos de vida y formas de habitar en la cultura que no dependen de las fórmulas patriarcales tradicionales, por eso, se deben tener en cuenta las diferentes formas de ser hombre o ser mujer más allá de la dicotomía tradicionalmente aceptada de hombre/mujer:

Teniendo en cuenta las críticas al carácter históricamente androcéntrico de los derechos humanos, basados en las experiencias de los hombres (blancos, adultos, heterosexuales, etc.), se han creado instrumentos que "amplían y reconocen esas especificidades de la diversidad humana". En ese sentido, el enfoque diferencial de derechos es un método de análisis y una guía para la acción que pretende hacer visibles las formas de discriminación "contra aquellos grupos o pobladores considerados diferentes por una mayoría o por un grupo hegemónico”. (MEN, 2018, p. 41)

El enfoque diferencial debe ser abordado desde una perspectiva institucional que promueva la satisfacción de necesidades existenciales y axiológicas de los miembros de una comunidad, en este caso, la comunidad universitaria, con el propósito de otorgarle a cada uno la titularidad en el obligatorio cumplimiento de los derechos. La educación superior con enfoque diferencial busca hacer:

[...] visibles las formas de exclusión de la educación superior de los estudiantes de los grupos mencionados, tomando en cuenta esta visibilización, brindar adecuada protección en el sistema. Se aclara, así mismo, que con este método se espera resolver las tensiones entre el enfoque inclusivo y el poblacional, articulando la priorización de los 
grupos con la "preocupación por las relaciones intersubjetivas entre todas y todos los estudiantes”. (MEN, 2018, p. 41)

\section{La violencia de género desde la narrativa del estudiante: construcción de sentido}

\section{Resultados}

La narración surge de la experiencia, que a su vez se constituye en un contexto y se evidencia a través de la palabra. En este sentido, para la categoría “Conceptos”, los estudiantes E1, E4, E14 y E15 definieron la violencia de género desde una perspectiva básica, relacionada con la subcategoría tipos de violencia, y desde la cual predominan las violencias: física, verbal y psicológica, entre el binarismo hombre/mujer.

Es la agresión física, verbal o psicológica que se presenta entre el género masculino y femenino por diversas índoles. (E1, comunicación personal, 3 de marzo de 2020)

Para mí la violencia es aquella que atenta y perjudica la salud de una persona por parte de otra (física, psicológica). (E4, comunicación personal, 3 de marzo de 2020)

Considero que la violencia de género es una agresión ya sea física o psicológica hacia la integralidad y bienestar de una persona. (E14, comunicación personal, 3 de marzo de 2020)

Considero que la violencia de género es cualquier conducta de violencia física o psicológica. (E15, comunicación personal, 3 de marzo de 2020)

De la categoría inicial también surge la subcategoría "Estados de Afectación", desde la cual se identifican en los discursos de los estudiantes palabras tales como libertad, discriminación, cultura, orientación sexual, estereotipo, género y sexo. Así, la concepción inicial relacionada con lo 
físico, lo psicológico y lo verbal se combina con otros conceptos a partir de los cuales la violencia por la condición de género adquiere relevancia en el contexto del relato. En este punto, la significación que cada uno hace de la violencia se bifurca en ámbitos que están determinados por la cultura e incluso por las mismas vivencias personales; de esta forma, la palabra es un síntoma que se manifiesta en dicha significación, se narra desde la propia experiencia y es posible comprender los diferentes fenómenos desde la situación, desde el ámbito de los acontecimientos.

Violencia de género es toda aquella acción influenciada por una cultura o actitud moral donde a un género o a los dos se le atribuyen características negativas, y que afectan a una persona o grupo basándose en estereotipos por el género, son simplificaciones de la complejidad humana de mujeres y hombres. (E2, comunicación personal, 3 de marzo de 2020)

Para mí la violencia de género es un tipo de discriminación que hace una persona a la otra, bien sea por su condición sexual o por el género al que pertenece afectando psicológicamente a la persona afectada. (E3, comunicación personal, 3 de marzo de 2020)

La violencia de género determina cómo una persona dialoga de forma incoherente e irrespetuosa acerca de su posición haciendo que el individuo se sienta impedido de ser libre y esto es un problema que no soluciona y por ende la sociedad impone también ese rechazo, lo cual hay que cambiar. (E3, comunicación personal, 3 de marzo de 2020)

Son los constantes irrespetos hacia la sociedad de parte de la misma sociedad con respecto a su color de piel (negro o blanco), con respecto a su orientación sexual, también por su manera de vestir, por sus gustos o preferencias. (E10, comunicación personal, 3 de marzo de 2020)

La violencia de género no solo se puede interpretar como el género con el que nacemos, también lo podemos ver frente a las identidades sexuales. 
Estos ámbitos de discriminación se ven en todos los aspectos sociales y

políticos donde se encuentra la humanidad. (E14, comunicación

personal, 3 de marzo de 2020)

Con respecto a la subcategoría “Ámbito Normativo”, los estudiantes en general desconocen la normativa que protege a las personas de cualquier tipo de violencia en razón de género, la gran mayoría de los estudiantes manifestaron no tener conocimiento de dichas normas o no reconocer su existencia, los estudiantes manifestaron conocer algunas bases jurídicas, sin embargo, su expresión fue ambigua e imprecisa. "[...] por medio de una acción de tutela, explicando paso a paso los ítems y acontecimientos surgidos por este" (E5, comunicación personal, 3 de marzo de 2020). Los estudiantes no tienen una perspectiva del recurso constitucional de la acción de tutela que les permita identificar si se trata del mecanismo correcto para enfrentar un acto de violencia de género, intrafamiliar o en el contexto de la universidad, por tanto, su expresión da cuenta del desconocimiento de la normativa:

Artículos de la Constitución que protegen la dignidad humana, el libre desarrollo de la personalidad, el derecho a la vida y el derecho a un cuerpo. (E7, comunicación personal, 3 de marzo de 2020)

La ley de la mujer, pero deberían existir algunas que reglamenten las acciones de los maestros y estudiantes con sus justas sanciones. (E5, comunicación personal, 3 de marzo de 2020)

La Ley 1257 que tipifica la violencia de género y sus tipos. (E15, comunicación personal, 3 de marzo de 2020)

Por consiguiente, existe una percepción ambigua y un claro desconocimiento de las rutas de atención en casos de violencia de género tanto en el mundo de lo jurídico como en la comunidad académica, a pesar 
de que algunos estudiantes mencionaron artículos constitucionales que, articulados a las leyes que los desarrollan, generarían una protección y garantía del ejercicio de los derechos con perspectiva de género.

Estas realidades se manifiestan en expresiones jurídicas que los estudiantes de primero y segundo año del programa de Derecho aún no tienen interiorizadas, de forma que no logran dar respuestas sustentadas en las normativas sustanciales y adjetivas desarrolladas en el ordenamiento jurídico y jurisprudencial colombiano.

Sin embargo, en correlación con lo anterior, la subcategoría "Garantía" representa un deseo de reivindicación de los derechos de las personas en relación con su condición de género. $\mathrm{Al}$ respecto, los estudiantes usan expresiones como "los actos violentos deben castigarse, se deben dar garantías a las personas que denuncian actos de violencia, se da naturalización a las agresiones que se viven a diario por tanto se hace más difícil proteger al as personas" (E5, comunicación personal, 3 de marzo de 2020).

Dichas expresiones se pueden observar en las respuestas de los estudiantes E18, E11 y E9:

Sí, es algo complicado de tipificar cada tipo de violencia y sobre todo el problema va de la mano con la naturalización de las agresiones que se viven a diario, y por lo regular afecta a los más desfavorecidos. (E18, comunicación personal, 3 de marzo de 2020)

[L]a justicia no prioriza a las víctimas y no le da magnitud a los hechos, por tanto, no se le dan garantías a la persona y esto hace que no sea efectivo. (E11, comunicación personal, 3 de marzo de 2020)

Ya que en la Constitución colombiana en su artículo primero dice que todos somos iguales ante la ley y que nada ni nadie puede violar los 
derechos fundamentales que todos los seres humanos tenemos por el simple hecho de ser personas, la justicia debería castigar a los violentos. (E9, comunicación personal, 3 de marzo de 2020)

Los casos de violencia de género que viven a diario los jóvenes, bien sea como testigos o como víctimas, obligan a pensar en los contextos discursivos que crean las condiciones subjetivas en las cuales la narración, como representación lingüística del acontecimiento, le da significación a la propia experiencia. "Ningún acontecimiento tiene un sentido en sí mismo, así como tampoco podemos afirmar que existen situaciones con valores universales que sean experimentadas de la misma manera por todos los seres humanos" (Fonseca, 2012, p. 8). Por esto dichas narraciones adquieren especial relevancia, pues surgen del sentir de cada uno de los estudiantes, así como de sus conceptos. "Las narrativas son los instrumentos primordiales para la creación y comunicación del significado. Desde una posición narrativa, los significados no están teorizados como representaciones o propiedades estables de un objeto en el mundo" (Domínguez y Herrera, 2013, p. 628), dado que todo lo que ocurre es dinámico e interdependiente en las relaciones en las que concurren los lenguajes y las creaciones culturales (Maceiras, 2002, p. 290).

Conozco de cerca la violencia psicológica y física, ya que veía cómo mi papá dañaba a mi mamá de manera psicológica, con comentarios que la hacían sentir inferior a todos, hasta el punto de aceptar el trato que recibía de mi papá y no solo le bastaba con dañarla con ese tipo de comentarios, sino que también lo hacía de manera física, ya que cada vez que quería se sentía con el derecho de agredirla y lastimarla. (E18, comunicación personal, 21 de octubre de 2020) 
En la categoría “Actitudes" se encuentran los textos producidos por los estudiantes, a partir de los cuales desarrollaron reflexiones en torno a la experiencia, es decir, no solo se cuenta el hecho ocurrido, sino que también se reflexiona sobre este exponiendo pensamientos, sentimientos y actitudes al respecto:

En otro salón un compañero molestó a una compañera poniéndole la maleta lejos, y luego tocándola en el cachete como disculpa, o no sé bien, la compañera le contestó irritada y molesta y apartándose inmediatamente. Lo considero violencia de género por el contexto y las actitudes machistas del compañero, un tipo de chantaje psicológico y dominio sobre ella. En el momento no lo entendí por ser algo sutil, $m i$ reacción fue seguir viendo para entender, porque mi intuición me decía que algo estaba mal, me siento decepcionado por ese compañero tan inmaduro y triste por la compañera; después hablé con ella al respecto y traté de construir a partir de esa mala experiencia. (E.2, comunicación personal, 3 de marzo de 2020)

La narrativa transcurre en la relación con el otro, pues se precisa un significado que requiere una condición de comprensión implicado en el relato, por ello "[...] la narración, el proceso discursivo, etc., son el dominio propio para su interpretación" (Maceiras, 2002, p. 290):

Experimenté un caso cercano de violencia de género en el cual una pareja tenía un carro, ellos se turnaban para manejar cuando iban al trabajo, cuando era el turno de la mujer el hombre siempre le decía cosas sobre su forma de manejar (que era lenta, que no sabía manejar, etc.) y la hacía sentir inferior con respecto a eso. Fue una situación incómoda, pienso que todos somos diferentes en lo que hacemos y por parte del hombre fue una mala actitud, siento que él quería sentirse superior porque yo estaba presente. (E3, comunicación personal, 3 de marzo de 2020) 
Los significados son construidos en el marco de las relaciones sociales, igualmente, las emociones se manifiestan como juicio en la interacción, al hablar en primera persona el narrador hace parte de la situación y se involucra cuestionando las actitudes, sin embargo, se distancia del hecho en cuanto no refiere una acción concreta para refrenar el acto en sí. "La capacidad de decir y de decirse para actuar, la cuestión de la relación recíproca que une indisolublemente el 'yo' al 'tú” (Amossy, 2010, p. 112), aquí hay un sujeto de la enunciación que se distancia de la situación, en una responsabilidad que le pertenece al otro.

En las narrativas expuestas se perciben aspectos lingüísticos comunes tales como el uso de la primera persona. "El 'yo' emerge y se da existencia como sujeto en el discurso, se dice y se muestra de una cierta manera" (Amossy, 2010, p. 112), a partir de la cual construye su identidad para sí y para los otros, pues el discurso necesariamente implica al otro, el "yo" está íntimamente relacionado con el "tú" en cuanto dialéctica del acontecimiento.

En el colegio donde yo estudié un chico de grado once se declaraba gay [...] él me pretendía a mí, éramos buenos amigos, pero empezó a ser muy afectivo a lo cual yo fui reacia, y el concluyó que no quería a las mujeres porque ellas no lo querían a él, con el pasar de tres meses en el colegio se dio a conocer la noticia de que él había sido declarado semiexpulsado por un problema en el cual él se exhibió fotográficamente con desnudez a otro hombre, y esto lo publicó en sus redes. A partir de alli él perdió los amigos que le quedaban, y unos pocos solo le hablaban para no hacerlo sentir mal, es decir, por lástima, y los demás de la promoción, algunos no le poníamos atención, lo evadíamos, lo ignorábamos, simplemente no nos metíamos con él y lo dejábamos con su vida en tanto no se metiera con nosotros, Sin embargo, varios chicos, solo hombres, lo abucheaban por "marica", diciéndole cosas hirientes y agrediéndolo, hacían ademanes de una persona travesti, de asco, de repulsión, se cubrían su 
parte genital y su parte posterior gritándole "no nos vaya a mirar de a mucho, que nosotros no somos maricas, ni ahuevados como usted".

Concluyó [en] que la psicóloga nos dio una charla casi que amenazando a quien lo ofendiera a expulsión, lo cual eliminó la violencia de género, y ya para el grado nadie lo miraba. Me sentí mal y culpable pues de alguna manera fui cómplice de la violencia, me da impotencia que muchas personas tengan un pensamiento errado y que se nieguen a aceptar al otro. (E4, comunicación personal, 3 de marzo de 2020)

Nótese que la narración comienza en primera persona, en un esfuerzo por dar sentido a la propia vida, desde la experiencia del acontecimiento, que le permite entrar en relación con el otro, y que no está exento de responsabilidad. Sin embargo, en un pretendido distanciamiento del hecho que considera más violento, el narrador se repliega, lo cual no implica que no participe directamente de esa dinámica social; y vuelve sobre sí mismo en la relación con el otro y con los otros, permitiéndose asumirse a sí mismo como corresponsable del hecho, en cuanto su reflexión se manifiesta en la culpa. "Se dice lo que somos y cómo queremos que los otros crean que somos mediante narrativas acerca de nosotros mismos y acerca de lo que pensamos que merece ser valorado" (Domínguez y Herrera, 2013, p. 632).

Así mismo, se usa el ejemplo para dar sentido a determinadas prácticas sociales, que expresan la valoración de la acción, su subjetividad está dada en el discurso de los valores, por ejemplo, en E9 y E10:

Cuando un padre de familia maltrata física y verbalmente a su pareja solo por el hecho de creerse superior por tener un título profesional y estar trabajando en un buen cargo. Esto me parece un acto de poca moral y machista, ya que a mi parecer todas las personas son iguales y no se identifican por la ausencia de un título profesional. Esta clase de actos me generan sentimientos de ira, de rencor, impotencia y desolación de 
ver una sociedad segada por la inmadurez de la evolución humana. (E9, comunicación personal, 3 de marzo de 2020)

Poniendo un ejemplo, la discriminación hacia las personas por ser de la comunidad LGBTI, donde solo por tener gustos diferentes a los acostumbrados normalmente lo llamen anormal o se use el término "marica", que aparte de ser una ofensa homofóbica también es violencia ya que jamás van a ser iguales a los demás, lo que me causa esto es rabia al saber que esto se fomenta por el entorno social en el que vivimos. (E1o, comunicación personal, 3 de marzo de 2020)

El sujeto rebela no solo la connotación incorrecta del acto de violencia de género, sino que lo sitúa frente al juicio de valor como un "yo" que no realiza la acción, pero que además la condena, aquí se manifiesta la capacidad del sujeto se ser sensible y, por lo tanto, ser afectado en sus sentimientos. La narración se da en marcas de subjetividad que constituyen su propia emoción.

Por su parte, la categoría "Prácticas Sociales" se enmarca en las acciones que el estudiante realiza o realizaría frente a la violencia de género, de manera que el contexto universitario se concibe como un escenario donde se pueden presentar no solo hechos de violencia sino también acciones reflexivas y protectoras.

Frente a la pregunta qué haría si se presentara un hecho de violencia de género en la universidad del que fuese testigo, los narradores se mostraron como accionantes, pues "la construcción narrativa de la identidad no está aislada del contexto social y cultural, sino que se produce en relación con ciertos interlocutores cruciales en los procesos de configuración del yo individual y colectivo" (Domínguez y Herrera, 2013, p. 633).

Creería que lo más importante sería auxiliar a la persona que es víctima, siendo un apoyo en el aspecto emocional. Amonestar a quien 
está realizando la agresión, ya que a veces necesitamos esa perspectiva que nos aterrice y haga ver nuestros errores. Con respecto a rutas de atención, me dirigiría a un docente de confianza. (E1, comunicación personal, 3 de marzo de 2020)

Depende de la gravedad, [si es] un acto físico grave actuaría inmediatamente con mis propias capacidades físicas y buscaría la ayuda inmediata de otros. Una violencia de ideas la manejaría primero hablando y de allí buscaría una autoridad de acuerdo al canal propio. (E2, comunicación personal, 3 de marzo de 2020)

En este caso, se hace manifiesto en el discurso el sentido de solidaridad en todos los estudiantes que ofrecen una respuesta ética, "una ética de la sensibilidad con el otro, y [...] el modo en que esta se expresa solo puede resolverse in situ, en cada situación, aquí y ahora" (Mèlich, 2013, p. 102).

Así mismo, la narración pone de manifiesto la solución de acudir a una persona con mayor autoridad para resolver la situación, como primera medida a docentes y luego a otras instancias.

En un primer momento intervengo yo para que esto no se siga dando, posterior hablaría con las partes involucradas en lo cual podría dar consejos y luego hablar con las personas encargadas de la disciplina y orientación psicológica de la universidad para ver si se puede llevar el caso especialmente. (E9, comunicación personal, 3 de marzo de 2020)

En primer lugar, hablaría con la persona que lo está haciendo, mostrándole que está mal lo que hace, luego buscaría orientación de un docente para saber qué hacer. (E12, comunicación personal, 3 de marzo de 2020)

Haría que el victimario se detuviera, apoyaría a la persona afectada para que hablara y no se sintiera culpable, ya que no importan los motivos por los que las personas dicen que somos culpables de ciertas agresiones, la 
víctima nunca es la culpable; llevaría el caso a las directivas y

presionaría para una solución pronta. (E14, comunicación personal, 3 de marzo de 2020)

Estas respuestas muestran que el estudiante está ávido de encontrar recursos en los cuales pueda apoyarse para realizar sus denuncias, el discurso se da en una práctica social que impulsa a la acción, esto es, se manifiesta la necesidad de encontrar ámbitos tanto de protección como de denuncia en los que los estudiantes se sientan validados en sus necesidades.

[La] narrativa puede contribuir a comprender y motivar a la acción comunicativa en ámbitos tan amplios y tan diversos como la dimensión relacional, los mundos personales, el fundamento sociocultural de las experiencias, la coherencia, los ciclos vitales y la vivencia corporal de la vida social. (Domínguez y Herrera, 2013, p. 637)

En la figura 1 se puede observar un resumen del proceso, a partir del cual se establecen las expresiones y palabras que constituyen las narrativas de los estudiantes acerca de los conceptos, actitudes y prácticas sociales que tienen desde una construcción descendente, es decir, desde la categoría como elemento general que enmarca la narración, hasta las subcategorías y entidades que particularizan el discurso de cada estudiante. En este sentido, se puede afirmar que las realidades humanas también se organizan como prácticas discursivas que construyen relaciones de sentido en el contexto. 
Figura 1. Narrativas de la violencia de género: conceptos, actitudes y prácticas sociales

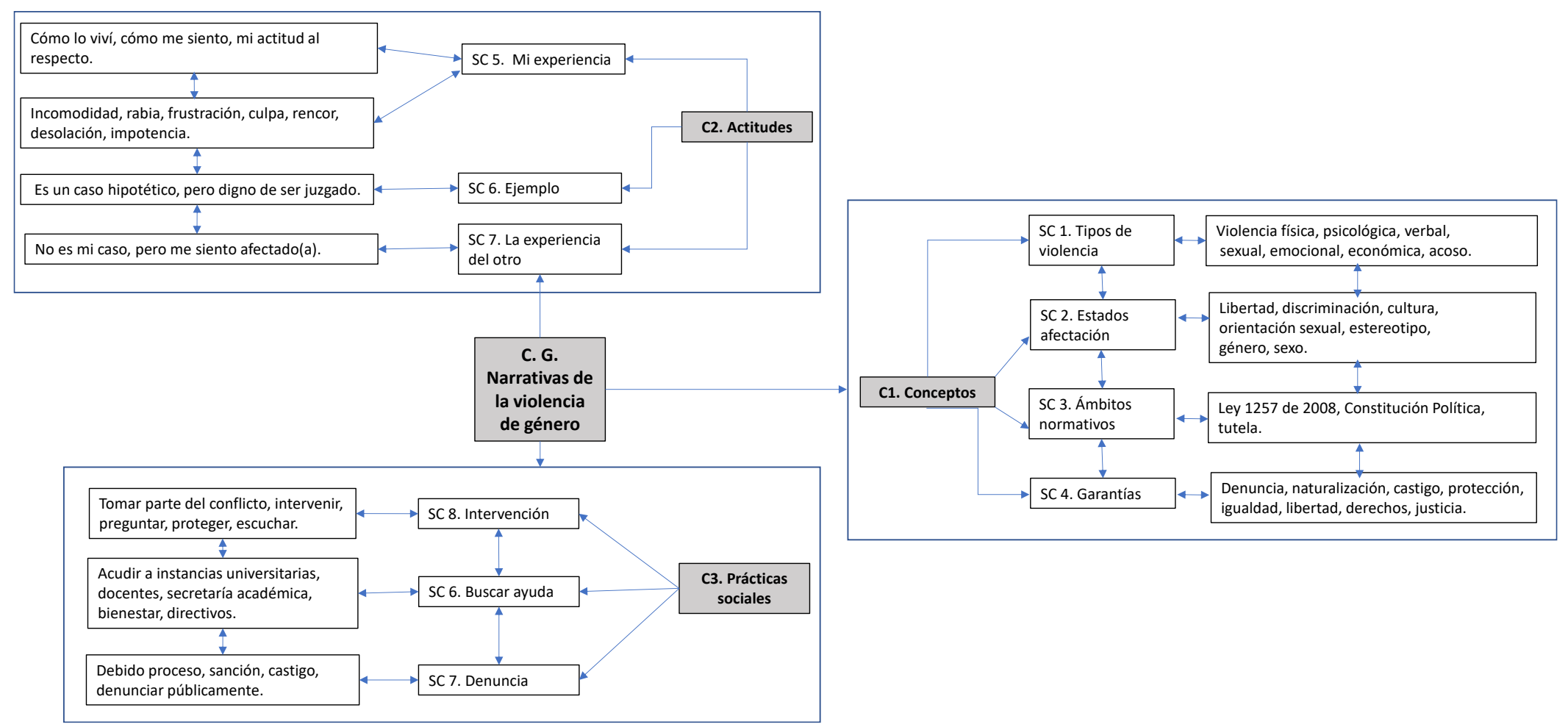

Fuente: elaboración propia. 


\section{Conclusiones}

La investigación desarrollada permite identificar la construcción de sentido que deviene de las realidades expuestas por los estudiantes de la Universidad Libre en la narración de sus experiencias y sentires sobre la violencia de género. Este hallazgo hace necesaria la construcción de una herramienta de protección a nivel institucional que reconozca y visibilice la violencia de género y las diferentes formas de discriminación a las que pueden estar expuestos los estudiantes en sus diferentes cotidianidades, en un intento por contribuir a la equidad de los géneros desde un enfoque diferencial.

El enfoque diferencial se construyó inicialmente a través de un protocolo institucional sobre violencias de género, violencias sexuales y rutas de atención para casos asociados a la violencia por razones de género, gracias a un grupo interdisciplinario compuesto por estudiantes, docentes, administrativos y directivos, fundamentado en la perspectiva de construcción colectiva de acción-participación. El documento, resultado de dicho trabajo colectivo, incluyó las acciones afirmativas a las cuales la Universidad se compromete con el enfoque diferencial de género, los marcos normativos y las sanciones tendientes a la protección de la persona en razón al género. Además del compromiso por institucionalizar el Observatorio Mujer, Género y Violencias, dependiente de la dirección seccional de investigaciones.

Así mismo, se llevó a cabo con estudiantes de primer semestre el taller denominado Derechos Personales: el Género, como un primer avance en la reflexión de esta temática, que pretendió dar a conocer a los estudiantes los conceptos asociados a las formas en las cuales pueden acceder a las diferentes rutas de atención establecidas para solucionar casos de violencia o discriminación relacionadas con género. 
En conclusión, las narrativas sobre la violencia de género producidas por los estudiantes de derecho de la Universidad Libre, Seccional Bogotá, permitieron evidenciar la necesidad de construir contextos de reflexión en torno a la temática y de incluir el enfoque diferencial de género en las prácticas universitarias.

Asimismo, comprender el contexto de las narrativas es construir diálogos cercanos a la experiencia del sujeto, quien, desde su propia condición de género, se nombra, se identifica y se construye. La palabra no es una unidad exclusivamente lingüística sino un valor connotado que le da sentido a la narración.

Por medio de las narrativas realizadas, los estudiantes visibilizaron sus necesidades de sentido, es decir, pensar, conceptualizar y expresar sus sentimientos sobre la violencia de género, así como establecer un propósito al asignarle valor a su propia experiencia, pues "el sentido no está al final del relato, sino que lo atraviesa” (Barthes, 1977, p. 11). Las narrativas como forma de interacción social construyen y reconstruyen significaciones, que son puestas en común a través de la apropiación del sentido, y le aportan valor a la propia experiencia. Las personas hablan desde su individualidad en contextos sociales mediados por la cultura. En otro sentido, analizar el problema de investigación de manera deductiva, desde la norma civilista, su contexto histórico y evolutivo, permitió revisar la noción de persona propia de la sistematización civilista y con ella la normatividad que ampara el reconocimiento de la dignidad humana y el derecho a no ser discriminado; también facilitó reconocer la importancia de un sistema normativo de la Universidad que propenda por la protección de la comunidad académica en torno al respeto y la no discriminación, que se materializó con la creación del protocolo y rutas de atención para la prevención, detección, atención y seguimiento de casos de 
violencias de género y violencias sexuales en la Universidad Libre (Resolución 03 del 13 de agosto de 2020).

Finalmente, es preciso reconocer la necesidad de que la Universidad incorpore más ampliamente la perspectiva de género y el enfoque diferencial de género en sus actuaciones, desde la docencia, el estudiantado y su planta directiva y administrativa, como compromiso de transformación en contextos de inclusión, equidad y no discriminación, en concordancia con su filosofía y principios institucionales.

\section{Referencias}

Amossy, R. (2010). Imágenes de sí, imágenes del otro. "Yo-Tú”. En La presentación de sí. Ethos e identidad verbal (pp. 111-133). Prometeo.

Arendt, H. (2006). Sobre la violencia. Alianza.

Bardin, L. (1996). Análisis de contenido. Akal.

Barthes, R. (1977). Introducción al análisis estructural de los relatos. Tiempo Contemporáneo.

Barthes, R. (1998). Fragmento de un discurso amoroso (14 ed.). (E. Molina, Trad.). Siglo XXI.

Benjamin, W. (1998). Para una crítica de la violencia y otros ensayos. Iluminaciones IV. Taurus.

Colombia. Ley 823 de 2003. Por la cual se dictan normas sobre igualdad de oportunidades para las mujeres. Julio 11 de 2003. D.O. núm. 45245.

Colombia. (2018). Código Civil. Legis.

Calsamiglia, H. y Tuson, A. (2002). Las cosas del decir. Manual de análisis del discurso. Ariel.

Comisión Interamericana de Derechos Humanos [CIDH]. (2015). Violencia contra personas LGBTI. Organización de los Estados Americanos. 
Consejo Nacional para la Prevención de la Discriminación [Conapred]. (2016). Glosario de la diversidad sexual, de género y características sexuales. https://www.conapred.org.mx/documentos_cedoc/Glosario_TDSyG_WEB.pdf

Constitución Política de Colombia [C.P.]. Art. 13. Julio 7 de 1991. http://www.constitucioncolombia.com/titulo-2/capitulo-1/articulo-13

Convención Americana sobre Derechos Humanos. (1969, 22 de noviembre). Derechos Humanos.Net. http://www.derechoshumanos.net/normativa/normas/america/CADH/1969CADH.htm\#: :text=la\%2oIntegridad\%20Personal-,1.,tratos\%2ocrueles\%2C\%20in humanos\%200\%20degradantes

Domínguez de la Ossa, E. y Herrera González, J. D. (2013). La investigación narrativa en psicología: definición y funciones. Psicología desde el Caribe, 30(3), 621-641.

Esguerra, C. (2011). Balances y perspectivas. Política Pública para la Garantía Plena de los Derechos de las Personas Lesbianas, Gays, Bisexuales y Transgeneristas (LGBTI) y Sobre Identidades de Género y Orientaciones Sexuales en el Distrito Capital. Mesa Intersectorial de Diversidad Sexual.

Facio, A. y Fries, L. (2005). Feminismo, género y patriarcado. Academia, 3(6), 259-294.

Fonseca, J. C. (2012). Reflexiones sobre la construcción narrativa de la identidad, crisis y afrontamiento. Psicoterapia y Familia, 25(2), 5-16.

Juárez Hernández, S. J. (2020). Culpa y castigo. Una explicación psicoanalítica. Vida Científica, 2(4). https://www.uaeh.edu.mx/scige/boletin/prepa4/n4/e18.html\#refe1

Maceiras, M. (2002). Metamorfosis del lenguaje. Síntesis.

Mazuera, P. (2019). Análisis del discurso jurídico desde el concepto de derecho a la igualdad de género en el marco de la hermenéutica constitucional de la corte constitucional (1992-2006). [Tesis de doctorado, Universidad Libre]. Repositorio Universidad Libre. https://repository.unilibre.edu.co/handle/10901/17689

Mèlich, J.-C. (2012). Filosofía de la finitud. Herder.

Mèlich , J.-C. (2013). Ética de la compasión. Herder. 
Ministerio de Educación Nacional [MEN]. (2017). Plan Nacional Decenal de Educación 2016-2026. El camino hacia la calidad y la equidad.

Ministerio de Educación Nacional [MEN]. (2018). Enfoque e identidades de género para los Lineamientos Política de Educación Superior Inclusiva.

Organización de los Estados Americanos [OEA]. (1995). Informe de la cuarta Conferencia Mundial sobre la Mujer, Beijing.

https://www.un.org/womenwatch/daw/beijing/pdf/Beijing\%2ofull\%2oreport\%20 S.pdf

Parada, M. y Uribe, L. (2017). Enfoque de género en el Acuerdo General para la Terminación del Conflicto. Observatorio de Restitución y Regulación de Derechos de Propiedad Agraria.

Rodríguez, A. (2014). Indicadores de constitucionalidad de las políticas públicas: enfoque de gestión de derechos. Via Inveniendi et Iudicandi, 9(2), 135-175.

https://doi.org/10.15332/s1909-0528.2014.0002.06

Semana. (6 de marzo de 2019). La violencia contra la mujer empeora en los últimos meses. https://www.semana.com/nacion/articulo/cifras-de-violencia-contra-lamujer-en-2018-y-2019/604118/

Universidad Libre. Resolución 03 del 13 de agosto de 2019. Por la cual se expide el protocolo y se establecen las rutas de atención para la prevención, detección, atención y seguimiento de casos de violencias de género y violencias sexuales en la Universidad Libre. http://www.unilibre.edu.co/la-universidad/ul/1675-resolucionn-03-de-2020-13-de-agosto

Van Dijk, T. A. (2008). El discurso como estructura y proceso. Estudios sobre el discurso I: una introducción multidisciplinaria. Gedisa.

Revista IUSTA

ISSN: 1900-0448 | e-ISSN: 2500-5286 | DOI: https://doi.org/10.15332/25005286

N. ${ }^{0} 55$ | julio-diciembre del 2021 